The American national collaborative perinatal study, also population based, provided similar results. In that cohort there were eight children who had at least one afebrile seizure lasting more than 30 minutes and had a sibling control. The mean IQ of the children with the seizures was just 1 point lower than that of the controls. $^{29}$

We thank the midwives, health visitors, general practitioners, medical records officers, and clinicians who provided essential information and also the children and their parents. Professor Neville Butler initiated the child health and education study, which was funded by the Medical Research Council, the Department of Health and Social Security, and the Gertrude H Sergievsky Center, Columbia University, New York. We are grateful to Sanofi-Winthrop for a grant to help with data analysis.

1 Leppick IE. Status epilepticus: the next decade. Neurology 1990;40(suppl 2): 4-9.

2 Aicardi J, Chevrie J. Convulsive status epilepticus in infants and children. A study of 239 cases. Epilepsia 1970;11:187-97.

3 Maytal J, Shinnar S, Moshe SL, Alvarez LA. Low morbidity and mortality of status epilepticus in children. Pediatrics 1989;83:323-31.

4 Maytal J, Shinnar S. Febrile status epilepticus. Pediatrics 1990;86:611-6.

5 Freeman JH. Status epilepticus: it's not what we've thought or taught Pediatrics 1989;83:444-5.

6 Hauser WA. Status epilepticus: epidemiologic considerations. Neurology 1990;40 (suppl 2):9-13.

7 Verity CM, Butler NR, Golding J. Febrile convulsions in a national cohort followed up from birth. I. Prevalence and recurrence in the first five years of life. $B M Y 1985 ; 290: 1307-10$

8 Verity CM, Butler NR, Golding J. Febrile convulsions in a national cohort followed up from birth. II. Medical history and intellectual ability at 5 years of age. $B M^{7}$ 1985;290:1311-5.

9 Verity $C M$, Golding J. Risk of epilepsy after febrile convulsions: a national cohort study. BMF 1991;303:1373-6.

10 Verity CM, Ross EM, Golding J. Epilepsy in the first 10 years of life: findings of the child health and education study. BMf 1992;305:857-61.
11 Chamberlain R, Chamberlain G, Howlett B, Claireaux A. British births 1970 Vol 1. The first week of life. London: Heinemann, 1975.

12 Commission on Classification and Terminology of the International League Against Epilepsy. Proposal for revised clinical and electroencephalographic classification of epileptic seizures. Epilepsia 1981;22:489-501

13 Oxbury JM, Whitty CWM. Causes and consequences of status epilepticus in adults. A study of 86 cases. Brain 1971;94:733-44.

14 Dunn DW. Status epilepticus in children: etiology, clinical features, and outcome. I Child Neurol 1988;3:167-73.

15 Wallace SJ, Cull AM. Long-term psychological outlook for children whose first fit occurs with fever. Dev Med Child Neurol 1979;21:28-40.

16 Fowler M. Brain damage after febrile convulsions. Arch Dis Child 1957;32: 67-76.

17 Falconer MA, Serafetinides EA, Corsellis JAN. Etiology and pathogenesis of temporal lobe epilepsy. Arch Neurol 1964;10:233-48.

18 Ounsted C, Lindsay J, Richards P. Temporal lobe epilepsy: a biographical study. London: MacKeith Press, 1987. (Clinics in developmental medicine No 103.)

19 Nelson KB, Ellenberg $\mathrm{JH}$. Prognosis in children with febrile seizures. Pediatrics 1978;61:720-7.

20 Ellenberg JH, Nelson KB. Febrile seizures and later intellectual performance. Arch Neurol 1978;35:17-21.

21 Aicardi J, Chevrie J-J. Consequences of status epilepticus in infants an children. In: Delgado-Escueta AV, Wasterlain CG, Treiman DM, Porter RJ, eds. Advances in neurology. Vol 34. Status epilepticus. New York: Raven Press, 1983:115-25.

22 Anon. Non-convulsive status epilepticus. [Editorial.] Lancet 1987;i:958-9.

23 Yager JY, Cheang M, Seshia SS. Status epilepticus in children. Can $f$ Neurol Sci 1988;15:402-5.

24 Phillips SA, Shanahan RJ. Etiology and mortality of status epilepticus in children. A recent update. Arch Neurol 1989;46:74-6.

25 Lothman E. The biochemical basis and pathophysiology of status epilepticus. Neurology 1990;40(suppl 2): 13-23.

26 Aicardi J, Baraton J. A pneumoencephalographic demonstration of brain atrophy following status epilepticus. Dev Med Child Neurol 1971;13:660-7.

27 Corsellis JAN, Bruton CJ. In: Delgado-Escueta AV, Wasterlain CG, Treiman DM, Porter RJ, eds. Advances in neurology. Vol 34. Status epilepticus. New York: Raven Press, 1983:129-39.

28 Soffer D, Melamed E, Assaf Y, Cotev S. Hemispheric damage in unilatera status epilepticus. Ann Neurol 1986;20:737-40.

29 Ellenberg JH, Hirtz DG, Nelson KB. Do seizures in children cause intellectua deterioration? N Engl f Med 1986; 314:1085-8.

(Accepted 13 May 1993)

\title{
Study of infection with HIV and related risk factors in young offenders' institution
}

\author{
A Graham Bird, Sheila M Gore, Sheila M Burns, John G Duggie
}

Immunology Department, Churchill Hospital, Headington, Oxford OX37 $\mathbf{L J}$

A Graham Bird, consultant immunologist

MRC Biostatistics Unit, Institute of Public Health, University Forvie Site, Cambridge CB2 2SR

Sheila M Gore, senior statistician

Regional Virus Laboratory, City Hospital, Edinburgh EH10 5SB

Sheila M Burns, consultant virologist

Group Medical Practice, The Health Centre, Grangemouth FK3 9EL John G Duggie, prison medical officer (part time)

Correspondence to: Dr Bird.
Abstract

Objectives-To estimate the prevalence of infection with HIV in young offenders in Scotland and to obtain information about related risk factors and previous tests for HIV.

Design-Voluntary anonymous study with subjects giving saliva samples for testing for HIV and completing questionnaires about risk factors.

Setting-Polmont Young Offenders' Institution near Falkirk, Scotland.

Subjects-421 of 424 available male prisoners in Polmont. The questionnaires of 17 of the prisoners were excluded because of inaccuracies.

Main outcome measures-Prevalence of infection with HIV and related risk behaviour.

Results-68 (17\%) of prisoners admitted misuse of intravenous drugs, of whom $17(25 \%)$ admitted having injected drugs while in prison. Three subjects admitted having anal intercourse while in prison. Prevalence of misuse of intravenous drugs varied geographically: $28 \%(33 / 120)$ of prisoners from Glasgow compared with $9 \%(7 / 81)$ of those from Edinburgh and Fife. A high level of heterosexual activity was reported, with $36 \%(142 / 397)$ of prisoners claiming to have had six or more female sexual partners in the year before they were imprisoned. Altogether 8\% (32/389) of prisoners had previously taken a personal test for HIV: $50 \%(9 / 18)$ of those who had started misusing intravenous drugs before $1989,18 \%(9 / 49)$ of those who started misuse later, and only $4 \%(14 / 322)$ of those who had not misused intravenous drugs. No saliva sample tested positive for antibodies to HIV, but 96 prisoners requested a confidential personal test for HIV as a result of heightened awareness generated by the study.

Conclusions-Voluntary, anonymous HIV surveys can achieve excellent compliance in prisons, and the interest generated by the study suggests that prisons may be suitable sites for providing education and drug rehabilitation for a young male population at high risk of future infection with HIV.

\section{Introduction}

In 1991 the Scottish Prison Service started a programme of serial anonymous surveillance of the prevalence of HIV and risk factors in selected establishments. The first studies were conducted by an external research team at HM Prison Saughton, Edinburgh, in August 1991 and October 1992. ${ }^{12}$ In 1992 surveillance was extended to Polmont Young Offenders' Institution, which is Scotland's largest establishment for young male offenders (aged 16-21). Prisoners in Polmont were invited to participate in a study of HIV prevalence, risk behaviours, and uptake of HIV tests by young males in the communities served by Polmont. We report these results and compare them with previously published results about Saughton's adult prisoners. ${ }^{12}$

\section{Subjects and methods}

Polmont Young Offenders' Institution, near Falkirk in Scotland's central region, serves the whole of 
Scotland. Its first voluntary anonymous HIV surveillance study was conducted on 28 October 1992 by an external team of 15 volunteers. Of the 449 young male offenders present at lock up on the previous evening, 424 were available to participate in the study: 16 were temporarily out of the prison (six at court and 10 on training for freedom), one had been liberated, and eight were unavailable because of being on governor's report. No prisoner was known to the Polmont medical staff to be infected with HIV, and none had asked for a confidential named HIV test before the study. ${ }^{3}$ Of the 424 available prisoners, $421(99 \%)$ participated in the HIV surveillance study by completing a questionnaire and providing a saliva sample. Questionnaires and saliva samples were linked by sealed number pairs (chosen at random by the prisoners) and samples were tested as described for the 1992 Saughton study. ${ }^{2}$ The same questionnaire was used as for the 1992 Saughton study except that the age groups for Polmont were under 18, 18-19, and 20-21.

\section{Results}

Of the 421 completed questionnaires, 17 contained logical errors in answers to questions about sentencing or use of intravenous drugs: six prisoners gave an inconsistent injecting history (two of whom had taken an HIV blood test), and, of the other 11, two prisoners were misusers of intravenous drugs (both of whom had taken the blood test for HIV) and a third had not answered the questions about use of intravenous drugs. We report the frequency distribution of answers from the 404 respondents whose questionnaires passed logical checks, of whom 68 had injected drugs not medically prescribed.

Of these 404 prisoners, 83 (21\%) were aged less than 18 , including nine $(13 \%)$ misusers of intravenous drugs. Altogether $123(30 \%)$ and $59(15 \%)$ of the prisoners resided in Glasgow and Edinburgh respectively. Table I shows that a significantly higher proportion of prisoners from Glasgow (28\%) reported having misused intravenous drugs than did those from Edinburgh or Fife $(9 \%)$ or elsewhere in Scotland $(14 \%)$. Of the 403 prisoners who gave the information, $142(35 \%)$ were serving their first sentence, but only 11 $(16 \%)$ of the 68 who were misusers of intravenous drugs were serving their first sentence. Only $10 \%(40 /$ 403) of prisoners were serving more than three years, but $37 \%(148 / 403)$ were serving one to three years. Misusers of intravenous drugs had spent more time in prison, $55 \%(36 / 66)$ having served more than one year, than non-misusers, of whom $31 \%(97 / 317)$ had served more than one year.

A high proportion (36\%) of all the prisoners had at some time been charged with a drugs related offence: $55 \%(36 / 66)$ of misusers of intravenous drugs and $32 \%$ $(104 / 329)$ of non-misusers $\left(\chi^{2}{ }_{1}=12 \cdot 6\right)$. The $17 \%(68 /$ $398)(95 \%$ confidence interval $13 \%$ to $21 \%$ ) of prisoners who had misused intravenous drugs was similar to the

TABLE I-Reported prevalence of having misused intravenous drugs among Polmont's prisoners by place of residence and previous imprisonments. Values are numbers (percentages) unless stated otherwise

\begin{tabular}{|c|c|c|c|}
\hline & \multicolumn{2}{|c|}{ Misuse of intravenous drugs } & \multirow{2}{*}{$\begin{array}{c}\chi^{2}{ }_{3} \\
\text { Value } \\
\text { (p value) }\end{array}$} \\
\hline & Never & Yes & \\
\hline $\begin{array}{l}\text { Place of residence } \\
\text { Edinburgh }(n=56) \\
\text { Fife }(n=25) \\
\text { Glasgow }(n=120) \\
\text { Elsewhere }(n=196)\end{array}$ & $\begin{array}{r}51(91) \\
23(92) \\
87(73) \\
168(86)\end{array}$ & $\begin{array}{l}5(9) \\
2(8) \\
33(28) \\
28(14)\end{array}$ & $\begin{array}{c}14 \cdot 3 \\
(0.003)\end{array}$ \\
\hline $\begin{array}{l}\text { No of previous imprisonmentst: } \\
\begin{array}{l}0(n=141) \\
1(n=79) \\
2-4(n=111) \\
\geqslant 5(n=67)\end{array}\end{array}$ & $\begin{array}{r}130(92) \\
62(78) \\
87(78) \\
51(76)\end{array}$ & $\begin{array}{l}11(8) \\
17(22) \\
24(22) \\
16(24)\end{array}$ & $\begin{array}{c}13.5 \\
(0.004)\end{array}$ \\
\hline
\end{tabular}

TABLE II-Reported number of female sexual partners in year before imprisonment among prisoners at Polmont and Saughton ${ }^{2}$ by prisoners' ages in 1992. Values are numbers (percentages) unless stated otherwise

\begin{tabular}{|c|c|c|c|c|c|}
\hline \multirow[b]{2}{*}{ Prisoner's ages (years) } & \multicolumn{4}{|c|}{$\begin{array}{l}\text { No of female sexual partners } \\
\text { in year before imprisonment }\end{array}$} & \multirow{2}{*}{$\begin{array}{c}\chi^{2} \\
\text { Test } \\
\text { (p value) }\end{array}$} \\
\hline & 0 & 1 & $2-5$ & $\geqslant 6$ & \\
\hline \multicolumn{6}{|l|}{ Polmont: } \\
\hline $\begin{array}{l}<18(n=82) \\
18-19(n=181) \\
20-21(n=134)\end{array}$ & $\begin{array}{l}3(4) \\
3(2) \\
4(3)\end{array}$ & $\begin{array}{l}10(12) \\
27(15) \\
27(20)\end{array}$ & $\begin{array}{l}39(48) \\
83(46) \\
59(44)\end{array}$ & $\begin{array}{l}30(37) \\
68(38) \\
44(33)\end{array}$ & $\begin{array}{c}x_{6}^{2}=4.0 \\
(0.67)\end{array}$ \\
\hline \multicolumn{6}{|l|}{ Saughton: } \\
\hline $\begin{array}{l}<26(n=86) \\
26-30(n=56)\end{array}$ & $\begin{array}{l}4(5) \\
5(9)\end{array}$ & $\begin{array}{l}20(23) \\
18(32)\end{array}$ & $\begin{array}{l}46(53) \\
25(45)\end{array}$ & $\begin{array}{r}16(19) \\
8(14)\end{array}$ & \multirow{3}{*}{$\begin{array}{c}\chi_{9}^{2}=19 \cdot 7 \\
(0.02)\end{array}$} \\
\hline $31-35(n=29)$ & $1(3)$ & $11(38)$ & $13(45)$ & $4(14)$ & \\
\hline$\geqslant 36(n=56)$ & $12(21)$ & $19(34)$ & $22(39)$ & $3(5)$ & \\
\hline
\end{tabular}

TABLE III-Reported prevalence of having been tested for HIV among Polmont's prisoners by place of residence and misuse of intravenous drugs. Values are numbers (percentage) unless stated otherwise

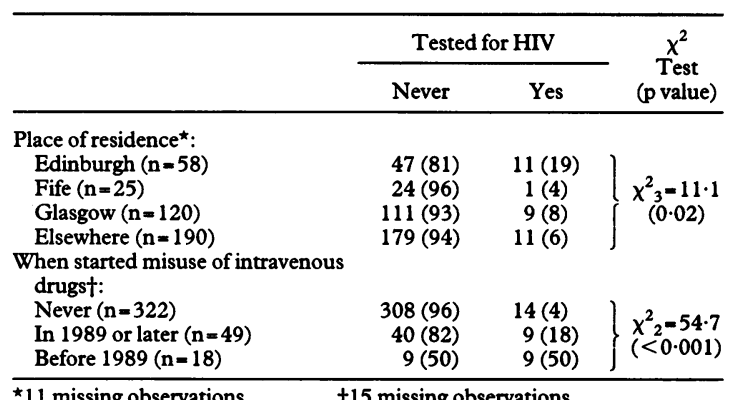

proportion among Saughton's adult male prisoners. ${ }^{12}$ Of the 68 misusers, 18 had started misuse before 1989 and 50 had started in 1989 or later. Altogether $25 \%$ (17/ 67) $(95 \%$ confidence interval $15 \%$ to $36 \%)$ of intravenous drug misusers had injected drugs while in prison, including $18 \%$ (9/49) of those who began injecting in 1989 or later. Intravenous drug misusers who had been charged with a drug related offence were more likely to have injected drugs in prison $(36 \%(13 /$ 36)) than those who had not been so charged $(14 \%$ $(4 / 29))\left(\chi^{2}=4 \cdot 1, p=0 \cdot 04\right)$. Only $4 \%(16 / 401)$ of all the prisoners had had an acute attack of hepatitis compared with $12 \%(8 / 67)$ of intravenous drug misusers.

The prisoners reported high numbers of female sexual partners in the year before their sentence began (14\% (57/397) claiming 11 or more partners), and the numbers where slightly higher among intravenous drug misusers. Table II shows that the number of reported female partners was similar for the three age groups of prisoners. Whereas 36\% (142/397) of Polmont's prisoners claimed to have had six or more female sexual partners in the year before their sentence, only $19 \%(16 / 86)$ of Saughton's adult male prisoners aged under 26 reported having done so. ${ }^{12}$ Of the 19 prisoners who reported having had male sexual partners in the year before their sentence began, nine gave an identical answer to the previous question about the number of female sexual partners, which suggests that they may not have noticed that the gender of sexual partner changed between questions. Of the three prisoners who reported having had anal intercourse with another man in prison, two reported having had intercourse with men in the year before their sentence began, but one of this pair had answered affirmatively to all questions about risk factors.

Only $8 \%(32 / 394)$ ( $95 \%$ confidence interval $5 \%$ to $11 \%$ ) of the prisoners had ever had a blood test for HIV compared with $26 \%$ and $38 \%$ of Saughton's prisoners who took part in the two HIV surveys. ${ }^{12}$ Table III shows that half $(9 / 18)$ of Polmont's prisoners who reported that they had started injecting drugs before 1989 had had a blood test for HIV, a significantly higher proportion than the $18 \%$ (9/49) of prisoners who began injecting drugs later $\left(\chi_{1}^{2}=6 \cdot 7, p=0 \cdot 01\right)$. All five of the intravenous drug misusers from Edinburgh had 
taken a test for HIV, but only $21 \%$ (7/33) of those from Glasgow and $22 \%(6 / 27)$ of those from elsewhere in Scotland had done so. Only 14 of the 322 who had not misused intravenous drugs reported having been tested for HIV. Of these 14, six were residents of Edinburgh, and table III shows that a significantly higher proportion of prisoners from Edinburgh had taken a test for HIV compared with those from the rest of Scotland $(19 \%(11 / 58) v 6 \%(21 / 335))$. Use of a linear logistic risk score, which has been described previously, ${ }^{1}$ showed that a prisoner's having been tested for HIV was not associated with aspects of sentencing, sexual behaviour, or age group.

Of the 421 prisoners who participated in the anonymous HIV surveillance, 96 spontaneously requested a confidential, personal test for HIV. Polmont Young Offenders' Institution had three trained HIV counsellors, and three HIV counsellors from the external team were diverted to counselling to help in dealing with the requests. The 96 men, who had requested a personal test for HIV on 28 October, were counselled by 4 November, and 60 confirmed their decision to have a test. Of the 421 samples of saliva received for testing, none was positive for antibody to HIV-1. Six equivocal results had required confirmation by Western blot but were shown to be negative.

\section{Discussion}

On 28 October 1992 Polmont's medical staff knew of no prisoners infected with HIV, and their impression was confirmed by negative results in all the saliva samples. Nevertheless, the self completed questionnaires showed that HIV risk activities were common among the prisoners, which gives no grounds for complacency in view of the high prevalence of HIV infection in parts of Scotland. The $99 \%$ volunteer rate was associated with a high number of requests for a confidential named HIV test; evidence of latent concern about HIV among the prisoners. We would advise that future studies in young offenders' institutions make prior provision to accommodate greatly increased requests for confidential named HIV tests. ${ }^{24}$ That so many young men sought a personal test at a time of heightened HIV awareness and when the requests could be made easily underlines how prisons can be used effectively by inmates to check their HIV status.

Polmont is Scotland's largest young offenders' institution, receiving young men from throughout Scotland. Misuse of intravenous drugs was more common among prisoners from Glasgow (28\%) than among those from Edinburgh and Fife (9\%) and from the rest of Scotland (14\%). This cannot be explained by different patterns of sentencing since similar proportions of prisoners from Edinburgh (36\%), Fife (36\%), and Glasgow (39\%) admitted previous drug offences. We speculate that the known high prevalence of HIV among misusers of intravenous drugs in Edinburgh, Dundee, and Fife; the intensive public health education campaigns, particularly in Edinburgh; and the priority given to the care of misusers of intravenous drugs in these regions, including substitution of drugs with methadone, has made an impact on the younger generation.

A quarter of intravenous drug misusers reported having injected drugs while in a young offenders' institution. Such prisoners, however, recognised the risks of their behaviour, as shown by the high risk scores of the prisoners who had been tested for HIV. These scores depended on when misuse of intravenous drugs began, if intravenous drugs had been used while in prison, and if a prisoner had had an acute attack of hepatitis. In Polmont, as in Saughton, ${ }^{12}$ we found that prisoners from Edinburgh were more likely to have had a test for HIV than those from the rest of Scotland.

\section{Public health implications}

- Inmates of prisons are perceived to be at particularly high risk of infection with HIV

- We found no prisoners to be infected with HIV at Polmont, Scotland's largest young offenders institution

- The high prevalence of risk behaviours among prisoners, however, indicates the need for future vigilance

- Our voluntary anonymous HIV testing met with excellent compliance

- This suggests that Scottish prisons are well placed to introduce initiatives such as easier access to testing for HIV and rehabilitation programmes for drug misusers

Our prison studies show that a high uptake of HIV testing has been achieved in regions where there is active encouragement of HIV testing, easy access to testing, and priority given to confidentiality.

Three prisoners reported having had anal sex with another man in prison. Two of these three also reported having had sex with men in the year before their sentence began and may, therefore, have been homosexual. Although this is clearly a risk behaviour for HIV infection, the three reports of anal intercourse should be compared with the 17 reports of misuse of intravenous drugs inside prison. We suggest that HIV education and priorities for risk reduction should be assigned accordingly.

Many prisoners reported high numbers of female sexual partners in the year before sentencing, higher than the numbers claimed by Saughton's adult male prisoners. Prisons and young offenders' institutions are enriched not only for men who have misused intravenous drugs ( $17 \%$ compared with $1 \%$ of the national male population aged under $\left.45^{5}\right)$, but also for men with high rates of change of female partners $(35 \%$ of young offenders compared with $2.5 \%$ of a general male population aged $18-19,{ }^{6}$ and $14 \%$ of Saughton's prisoners aged $26-35$ compared with $1.3 \%$ of males in the general population aged 26-35). These high levels of HIV risk behaviours emphasise the importance of HIV surveillance for prison populations and the vulnerability of such populations to rapidly emerging HIV infection.

The Scottish Prison Service's policy of universal education of staff and inmates and integration of HIV infected inmates has engendered a climate of trust that is manifested by high compliance with voluntary anonymous HIV surveillance. Scottish prisons are well placed to introduce further initiatives, including easier access to testing for those at risk of HIV infection and rehabilitation programmes for drug users.

We thank Mr George Shearer, governor of Polmont Young Offenders' Institution; Miss J Ivol, lecturer in education; Mr R Muir, principal nursing officer; and Mr R Cooke and Mr A Main, senior nursing officers, for help in conducting this study. Dr J Basson and Dr Rosalind Skinner of the Scottish Home and Health Department were supportive, and the study was funded by a grant from the Chief Scientist for Scotland.

\section{Appendix}

The 1992 volunteer Saughton and Polmont study team comprised Ms Marian Aldhous, Dr Graham Bird, Mrs Pat Bolam, Mr Neil Burrells, Ms Nessa Carey, Sister Anne Chiswick, Dr Tony Davies, Ms Maggie Gray, Mrs Liz 
Greenwood, Dr Sheila Gore, Dr Gwyneth Jones, Dr Linda McCallum, Mrs Marian McGill, Dr Gillian Raab, Sister Fiona Raeside, Mr Peter Ronald, Ms Alison Rowlands, Ms Rebecca Temperley, Dr Edwin Van Teijlingen, Dr Eric Walker, Sister Jenny Whelans, Mr Jim Whitelaw, Ms Lynn Williamson, and Ms Gill Young.

1 Bird AG, Gore SM, Jolliffe DW, Burns SM. Anonymous HIV surveillance in Saughton prison, Edinburgh. AIDS 1992;6:725-33.

2 Bird AG, Gore SM, Jolliffe DW, Burns SM. Second anonymous HIV surveillance and in Saughton prison, Edinburgh: prisoners give a lead to other heterosexuals on being HIV tested. AIDS (in press).

3 Gore SM, Basson J, Bird AG, Goldberg DJ. Uptake of confidential, named HIV testing in Scottish prisons. Lancet 1992;340:907-8.

4 Gore SM, Jolliffe DW, Bird AG. Prisoners' uptake of confidential named HIV testing. Lancet 1992;339:1491-2.

5 Johnson AM, Wadsworth J, Wellings $K$, Bradshaw S, Field J. Sexual lifestyles and HIV risk. Nature 1992;360:410-2.

6 ACSF Investigators. AIDS and sexual behaviour in France. Nature 1992;360: 407-9.

(Accepted 17 May 1993)

\title{
Lifelong exercise and stroke
}

\author{
Roger Shinton, Gian Sagar
}

\begin{abstract}
Objectives-To examine the potential of lifelong patterns of increased physical activity to prevent stroke.

Design-Case-control study.

Setting-11 general practices in west Birmingham.

Subjects-125 men and women who had just had their first stroke and were aged 35-74 and 198 controls frequency matched for age and sex recruited over 24 months during 1988-90. Exclusion criteria were a previous history of stroke, mitral valvular heart disease combined with atrial fibrillation, primary or metastatic cerebral neoplasm, or coagulation disorder or myeloproliferative disease.

Main outcome measures-Odds ratios for stroke related to lifetime history of exercise after 15 years of age.
\end{abstract}

Results-A history of vigorous exercise during the ages 15-25 appeared to protect from stroke: odds ratio adjusted for age and sex 0.33 (95\% confidence interval 0.2 to 0.6 ). This effect was independent of other potential risk factors. Increasing years of participation in vigorous exercise between the ages of 15 and 55 produced an increasing protection from stroke $(p<0.001)$. In the 65 cases and 169 controls who were free of cardiac ischaemia, peripheral vascular disease, and poor health recent vigorous exercise and walking were protective against stroke: odds ratios of $0.41 \quad(0.2$ to 1.0$)$ for recent vigorous exercise and $0.30(0.1$ to 0.7 ) for recent walking.

Conclusions-Appreciable protection from stroke in later life is conferred by vigorous exercise in early adulthood. This increased level of physical activity should, if possible, be continued lifelong.

University of Birmingham, Department of Medicine, Dudley Road Hospital, Birmingham B18 7QH Roger Shinton, Wellcome Trust fellow in clinical epidemiology

Department of Radiology, Dudley Road Hospital Gian Sagar, consultant radiologist

Correspondence to: Dr Shinton, University of Birmingham, Department of Geriatric Medicine, The Hayward Building, Selly Oak Hospital, Birmingham B29 6JD.

$B M 9$ 1993;307:231-4

\section{Introduction}

Evidence is growing that exercise can protect against stroke, ${ }^{1}$ but increased levels of physical activity are not yet widely recognised protective factors for stroke. ${ }^{2-4}$ There is, however, a more general acceptance that exercise reduces risks of coronary heart disease and hypertension. ${ }^{47}$ The importance of exercise in early adult life in protection from stroke has received little attention. This is somewhat surprising because a history of recent exercise is closely related to overall general health. Thus the relation between stroke and recent exercise can be confounded by illnesses which limit exercise and predispose to cerebrovascular events. This confounding should be minimal when exercise in early adulthood is examined.

In one cohort study examining the importance of exercise in youth participation in university sports was associated with a later reduction in the risk of fatal stroke. $^{8}$ This, however, was not confirmed in the college alumni with non-fatal strokes. ${ }^{9}$ The influence of potential confounding variables was not examined in these analyses.

The west Birmingham stroke project, a community based case-control study, was designed to examine risk factors for stroke in people's lifestyles, including lifelong patterns of exercise.

\section{Subjects and methods}

The detailed methods of the case-control study have been described previously. ${ }^{10}$ People registered with 11 general practices in west Birmingham comprised the study population of 101000

\section{SUBJECTS}

Between 1 October 1989 and 30 September 1990 we recruited men and women who had just had their first stroke and were aged 35-74. To ensure maximum recruitment each general practice was phoned weekly, and the admission records of Dudley Road Hospital were regularly checked for patients with entries suggestive of stroke. The patients were assessed by one of us (RS) using the standard criteria of the World Health Organisation: rapidly developing clinical signs of focal and, at times, global (applied to patients in deep coma or with subarachnoid haemorrhage) loss of cerebral function with symptoms lasting more than 24 hours or leading to death and with no apparent cause other than that of vascular origin. ${ }^{11}$ Both hospital and community based patients with stroke were, if fit, offered computed tomography of the head (without contrast). The scans were reported by one of us (GS). Cerebral infarction was diagnosed if a head scan or autopsy was performed within 21 days of the start of a stroke and there was either no evidence of haemorrhage or a pattern of predominant infarction.

Patients were excluded from the study if they had a prior history of stroke (but not transient ischaemic attack), a history of mitral valvular heart disease combined with atrial fibrillation, a history of primary or metastatic cerebral neoplasm, or a history of coagulation disorder or myeloproliferative disease. Patients who died before assessment could be made and those who refused to participate were also excluded.

Control subjects were randomly selected from the general practice population to broadly match the distribution of age and sex among the patients with stroke (frequency matching). All those on the registers of the 11 participating practices aged $35-74$ were eligible for inclusion. The same exclusions applied as for the patients with stroke. The controls were each sent a letter signed by their general practitioner, which was followed up by a telephone call or visit to arrange an appointment for assessment, usually at their practice surgery. 